\title{
Association between periodontitis and severe asthma in adults: A case-control study
}

\author{
Kaliane Rocha Soledade-Marques ${ }^{1}$ | Isaac Suzart Gomes-Filho ${ }^{1}$ (D) | \\ Simone Seixas da Cruz ${ }^{1,2}$ | Johelle de Santana Passos-Soares ${ }^{3}$ | Soraya Castro Trindade ${ }^{1}$ | \\ Eneida de Moraes Marcílio Cerqueira ${ }^{1}$ | Julita Maria Freitas Coelho ${ }^{4}$ | \\ Maurício Lima Barreto ${ }^{5,6}$ | Maria da Conceição Nascimento Costa ${ }^{5}$ | \\ Maria Isabel Pereira Vianna ${ }^{3}$ | Frank A. Scannapieco ${ }^{7}$ | Álvaro Augusto Cruz ${ }^{8}$ | \\ Adelmir Souza-Machado ${ }^{8,9}$
}

\author{
${ }^{1}$ Department of Health, Feira de Santana State \\ University, Feira de Santana Bahia, Brazil \\ ${ }^{2}$ Department of Epidemiology, Federal \\ University of Recôncavo da Bahia, Santo \\ Antônio de Jesus, Bahia, Brazil \\ ${ }^{3}$ Department of Preventive Dentistry, Federal \\ University of Bahia, Salvador, Bahia, Brazil \\ ${ }^{4}$ Department of Biological Sciences, Feira de \\ Santana State University, Feira de Santana, \\ Bahia, Brazil \\ ${ }^{5}$ Department of Collective Health, Institute of \\ Collective Health, Federal University of Bahia, \\ Salvador, Bahia, Brazil \\ ${ }^{6}$ Oswaldo Cruz Foundation, Research Center \\ Gonçalo Muniz - FIOCRUZ, Salvador, Bahia, \\ Brazil \\ ${ }^{7}$ Department of Oral Biology, University of \\ Buffalo, Buffalo, NY, USA \\ ${ }^{8}$ ProAR - Núcleo de Excelência em \\ Asma, Federal University of Bahia, Salvador, \\ Bahia, Brazil \\ ${ }^{9}$ Department of Biomorphology, Federal \\ University of Bahia, Salvador, Bahia, Brazil \\ Correspondence \\ Isaac Suzart Gomes-Filho, \\ Department of Health, Feira de Santana State \\ University, Feira de Santana Bahia, Brazil. \\ Email: isuzart@gmail.com \\ Funding information \\ Alvaro A. Cruz, Grant/Award Number: CNPq/ \\ FAPESB - PRONEX - 6353 - PNX0018/2009
}

Objective: To evaluate the association between periodontitis and severe asthma, with participants in treatment for severe asthma, controlled by therapy.

Methods: A case-control investigation was performed to compare 130 adults with severe asthma with 130 without asthma. Individuals with periodontitis were those with $\geq 4$ teeth with $\geq 1$ site with probing depth $\geq 4 \mathrm{~mm}$, clinical attachment level $\geq 3 \mathrm{~mm}$, and bleeding upon probing at the same site. Severe asthma diagnosis was based on Global Initiative for Asthma criteria.

Results: Association between exposure to periodontitis and severe asthma was found: $\mathrm{OR}_{\text {crude }}=2.98$ (95\% Cl: 1.74-5.11). When confounders were considered, the association between exposure to periodontitis and severe asthma was maintained: $\mathrm{OR}_{\text {adjusted }}=3.01-3.25$. Individuals with periodontitis had about a threefold increased risk of severe asthma than those without periodontitis. Frequency of periodontitis in participants with severe asthma was greater than that of those without asthma $(46.6 \%$ vs $22.3 \%, p \leq .05)$.

Conclusions: Association between periodontitis and severe asthma was observed. Further investigation is required to determine the direction of this relationship. It may be causal, but it may also be a consequence of the immunopathological process that characterizes asthma, or else, consequence of the medication used for treatment.

KEYWORDS

asthma, bronchial inflammation, epidemiology, periodontal disease, periodontitis

\section{1 | INTRODUCTION}

Both periodontitis and asthma are complex diseases with high prevalence worldwide. Approximately $20 \%$ of all adults demonstrate evidence of periodontitis (Genco \& Borgnakke, 2013), while asthma affects some 334 million people of all ages (GINA, 2014), 10\% of which are severe (WHO, 2011). Few studies have addressed the influence of periodontitis on asthma (Friedrich et al., 2006; Gomes-Filho 
et al., 2014; Laurikainen \& Kuusisto, 1998; Rivera, Andriankaja, Perez, \& Joshipura, 2016; Stensson et al., 2011; Yaghobee, Paknejad, \& Khorsand, 2008).

Previous work from our group (Gomes-Filho et al., 2014) showed a strong positive association between periodontitis and asthma severity. In view of these results, the following questions were posed: does the association remain strong with participants of the case group when severe asthma is adequately controlled by therapy? Does the inclusion of different confounders in the analysis model influence the strength of this association?

Despite the association between periodontitis and asthma, a causal link is not established. To demonstrate a causal link, several mechanisms must be established to prove this association (Mehta, Sequeira, Sahoo, \& Kaur, 2009). Matrix metalloproteinase, released from inflammatory cells present in periodontitis, could degrade structural proteins within the respiratory tissue, possibly resulting in chronic bronchial inflammation and the establishment of asthma (Gueders, Foidart, Noel, \& Cataldo, 2006). It can also be hypothesized that the typical and abundant microbial population associated with periodontitis might influence the lower airway microflora, generating an imbalance that favors the initiation or progression of asthma. (Navarro, Nelson Filho, Silva, \& Freitas, 2006).

There is also the possibility that these diseases are not causally related and are linked only by chance, or by common risk factors (Arbes \& Matsui, 2011; Matsui, 2012). The aging population who now maintain larger numbers of teeth and factors related to urbanization and the risk of asthma, together, may make the population more vulnerable to these diseases. In addition, harmful behaviors such as smoking might contribute to both periodontitis and asthma progression (Cerveri et al. 2012; Papapanou, 1998).

Socioeconomic characteristics, such as education and income level, also have a strong effect on the occurrence of both diseases. The prevalence of asthma and periodontitis is very often higher in those with lower educational levels and income (Davoodi, Mahesh, Holla, \& Ramachandra, 2013; Wennström, Ahlqwist, Stenman, Björkelund, \& Hakeberg, 2013).

Most existing studies of the link between periodontitis and asthma have included relatively small sample sizes (Gomes-Filho et al., 2014; Laurikainen \& Kuusisto, 1998; Stensson et al., 2011; Yaghobee et al., 2008) and have not investigated the individuals' response to therapy (Friedrich et al., 2006; Laurikainen \& Kuusisto, 1998; Rivera et al., 2016; Yaghobee et al., 2008), and confounders in the analysis models (Stensson et al., 2011; Yaghobee et al., 2008). This study has addressed the methodologic shortcomings of previous studies.

Thus, the goal of this study was to estimate the association between periodontitis and severe asthma, with participants with severe asthma controlled by therapy, and to explore the possible influences of socioeconomic-demographic, lifestyle, and health factors on this association.

\section{2 | MATERIALS AND METHODS}

This case-control investigation was conducted from January 2013 to November 2014 in the Program for Control of Asthma in Bahia
(ProAR), Salvador, Bahia, Brazil. The Research Ethics Committee of Climério de Oliveira Hospital, Federal University of Bahia (CONEP $n^{\circ}$ 15782), approved the study, in accordance with the Declaration of Helsinki.

\section{1 | Sample size}

The following parameters were used to calculate the minimum sample size: a $95 \%$ confidence level, $80 \%$ study power, an estimated frequency of periodontitis of $30.3 \%$ in individuals with no asthma diagnosis (control group) and $49.7 \%$ in those with severe asthma (controlled, case group), based on data from a pilot study (unpublished data). Thus, an estimated minimum number of participants in both the case and control groups was 103, approximately, totaling 206 individuals.

\section{2 | Criteria for sample selection}

The case group was composed of adults (age $\geq 18$ years) with diagnosis of asthma, defined as severe at the moment of their enrollment in the ProAR central reference clinic cohort, according to GINA classification of 2002. Asthma was defined as having symptoms including episodic breathlessness, cough, wheezing, and chest tightness. Seasonal variability of symptoms and a previous history of asthma and atopic disease in the family were useful diagnostic aids. The control group was composed of individuals with no history of asthma, mostly from those who sought other services available at the health center. No relatives or spouses were recruited to reduce the chance of similar genetic or environmental risk exposure. Thus, the participants in the case and control groups were derived from the same population. For each participant found with severe asthma, case group, another was selected without asthma, control group. All participants were $\geq 18$ years old and with a minimum of four teeth present to ensure the measurements of periodontal status. The participation of the individuals for the research was voluntary and all signed a free and informed consent form.

\section{3 | Data-gathering procedures}

Asthma diagnosis was confirmed by a pulmonary physician from ProAR team, who also defined whether it was severe or not, based on GINA criteria (GINA, 2002). Prior to the inclusion in the current casecontrol study, an audit was conducted on the charts of all individuals with severe asthma, and only those for which there was an agreement on the diagnosis of asthma by two experts and a spirometry confirming the diagnosis were invited to take part.

Data on socioeconomic, demographic, lifestyle habits, oral and general health condition, and dental care were collected using a questionnaire. The observer was blinded to asthma status of the participants while they underwent a complete oral examination, performed by one periodontist (KS-M), who was trained by a senior periodontist (IG-F). The full examination was conducted, except for third molars, using a periodontal probe (Hu-Friedy, Chicago, IL) for six sites per tooth: 
mesio-, mid-, and disto-buccal, mesio-, mid-, and disto-lingual. From this information, the following were calculated: recession measure, probing depth, clinical attachment level, bleeding upon probing, and visible plaque index. The probing depth was determined to be the distance between the gingival margin and the greatest penetration of the probe. The presence of recession was identified as the distance between the gingival margin and the cementum-enamel junction. The clinical attachment level was the sum of the values of probing depth measures and recession. Bleeding upon probing was defined as bleeding present within $10 \mathrm{~s}$ of the probe's removal. Visible plaque was examined at four sites, mesial, buccal, distal, and lingual, using the probe only to confirm the presence of plaque on the tooth surface. Intra- and interexaminer reliability of recession and probing depth measurements was calculated using Kappa index (difference of $\pm 1 \mathrm{~mm}$ ), with correlation of 0.81 and 0.84 , and 0.80 and 0.83 , respectively, in $10 \%$ of the sample.

\section{4 | Definition of exposure and outcome}

Individuals diagnosed with periodontitis (exposure) had a minimum of four teeth with at least one site possessing probing depth greater than or equal to $4 \mathrm{~mm}$, clinical attachment level greater than or equal to $3 \mathrm{~mm}$, and bleeding upon probing at the same site. (Gomes-Filho et al., 2007).

This diagnosis of the outcome-controlled severe asthma-was in accordance with the Global Initiative for Asthma (GINA, 2002), in which individuals who presented at least one of the following criteria upon registering in the reference center (ProAR): 1 ) daily symptoms over the last 4 weeks; 2) frequent exacerbations; 3) frequent nocturnal asthma symptoms; 4) limitation of physical activities; and 5) forced expiratory volume in one-second $\left(\mathrm{FEV}_{1}\right)$ or peak expiratory flow rate (PEF) $\leq 60 \%$ of predicted.

\section{5 | Statistical analyses}

Summary descriptive analyses were conducted for the following: age, gender, self-reported skin color, schooling level (years of study), household density (number of people), marital status, family income (minimum monthly salaries), smoking habit, physical activity, last visit to dentist, mouth-breathing habit, brushing frequency, use of dental floss (a minimum of once a day), hypertension, diabetes, osteoporosis, hypercholesterolemia, cardiovascular disease, body mass index-BMI $\left(\mathrm{kg} / \mathrm{m}^{2}\right)$, bleeding upon probing, plaque index, number of present teeth, number of sites with clinical attachment level 1-2 mm, 3-4 $\mathrm{mm}$, and $\geq 5 \mathrm{~mm}$, and number of sites with probing depth $\geq 4 \mathrm{~mm}$. Simple frequencies and central tendency measurements were obtained. The $\chi^{2}$ test and the $t$ test, for categorical and continuous covariables, respectively, were used in bivariate analysis, with a significance level of $p=5 \%$, to know how different the covariables in the comparison groups were. Odds ratio (OR) and 95\% confidence interval were used to estimate the magnitude of the association between exposure to periodontitis and severe asthma. Stratified and logistic regression analyses were also conducted. The investigation of the presence of effect-modifying covariables used the maximum-likelihood ratio test $(p=5 \%)$, and the evaluation of the presence of confounders by means of backward strategy. If the covariable produced an alteration of at least $10 \%$ in the association measurement, it was defined as a confounder.

Additionally, those covariables that have an influence on both periodontitis and on severe asthma in accordance with previous studies on the theme were also considered confounding covariables. Therefore, nine adjusted final models were generated in accordance with alteration of different confounding covariables. The relative differences were obtained by the subtraction of the adjusted and crude association measurements, divided by the crude measurement: Relative difference $=\left(O R_{\text {adjusted }}-O R_{\text {crude }} / O R_{\text {crude }}\right) \times 100$.

The Hosmer-Lemeshow statistic was used to evaluate the goodness of fit of the regression model employed in the study. The results were analyzed using two software packages (Stata Data Analysis and Statistical Software, StataCorp LP, College Station, TX; and SPSS Software v.21.0, IBM, Armonk, NY).

\subsection{Confounder selection procedure}

The selection of confounder covariable was initially based on their distribution in the study groups and confirmed by the strategies used in the statistical analysis. In addition, the selection was also based on the epidemiological importance of the covariable in previous studies (Friedrich et al., 2006; Gomes-Filho et al., 2014; Laurikainen \& Kuusisto, 1998; Rivera et al., 2016). The covariables such as age, schooling level, family income, household density, osteoporosis, hypertension, diabetes, smoking habit, and BMI were chosen and composed the different models of analysis in accordance with the conceptual framework addressed in the discussion section. The confounders of the first adjusted model were selected based on the previous study of Gomes-Filho et al., 2014. The covariables maintenance in each model followed the criterion of choosing only one representative per confounder group, for example, demographic (age), socioeconomic condition (schooling level, family income, household density), health condition (osteoporosis, hypertension, diabetes), life style (smoking habit), and nutritional condition (BMI).

\section{3 | RESULTS}

The final sample of this study consisted of 260 participants, 217 women and 43 men, with an average age of $48.2 \pm 14$ years (standard deviation), median of 49 years, with a minimum of 18 and a maximum of 89 years. Of these, 130 individuals ( 17 males and 113 females) made up the control group with no diagnosis of asthma and 130 individuals ( 26 males and 104 females) served as the case group with a diagnosis of severe asthma.

In total, 89 (34.23\%) individuals were classified as having periodontitis, 29 participants in the control group and 60 in the case group. The visible plaque (PI) and bleeding upon probing indexes (BOP) showed the worst conditions in the group of individuals with severe asthma (PI: $44.35 \%$ vs $29.57 \%$ and BOP: $21.47 \%$ vs $12.68 \%$ ). 
The socioeconomic, demographic, medical, and oral characteristics of the comparison groups are provided in Table 1. The groups under study were generally homogeneous for the majority of the evaluated characteristics, with a statistically significant difference only being noted for age $(p<.01)$, schooling level $(p=.01)$, family income $(p=.03)$, mouth-breathing habit $(p<.01)$, presence of periodontitis $(p<.01)$, and hypertension $(p=.02)$.

Table 2 shows other characteristics related to periodontal condition of the study groups. The cases had more frequent bleeding upon probing $(p<.01)$ and visible plaque indexes $(p<.01)$ in comparison with the control group. In contrast, the number of present teeth $(p=.05)$ and sites with clinical attachment level 1-2 mm ( $p=.02)$ was statistically greater in the control group.

The crude and adjusted measurements for the association between exposure to periodontitis and severe asthma are shown in Table 3. The crude association analysis found that, in individuals with periodontitis, the chance of having severe asthma was, approximately, three times greater than in participants without periodontal disease $\left[\mathrm{OR}_{\text {crude }}=2.98(95 \% \mathrm{Cl}: 1.74-5.11)\right]$.

Stratification analysis found neither modifier covariables nor confounders, thereafter confirmed by logistic regression analysis. As such, to obtain the adjusted association measurement, the covariables age, schooling level, osteoporosis, smoking habit, and body mass index were selected and included in the first analysis model due to their epidemiological relevance in asthma and/or periodontitis, based on Gomes-Filho et al., 2014.

In the logistic regression model, the adjusted association measurement was $\mathrm{OR}_{\text {adjusted }}=3.18(95 \% \mathrm{Cl}: 1.80-5.63)$. However, when the analysis model was altered in accordance with the type of covariable, some changes were found in the association measurement (Table 3). The variation of the magnitude of the adjusted measurements ranged from $\mathrm{OR}_{\text {adjusted }}=3.01-3.25$, always with a narrow $95 \% \mathrm{Cl}$ and above 1 . The greatest relative differences were observed in the following adjusted models: model 1 (6.71\%), model 4 (7.72\%), and model 7 (9.06\%).

The Hosmer-Lemeshow statistic was employed to evaluate the goodness-of-fit diagnosis of the regression models used. There was a $p$ value ranging from 0.23 to 0.79 , and the null hypothesis was not rejected, indicating an acceptable goodness of fit for the regression models.

\section{4 | DISCUSSION}

The findings of the present study showed a strong association between exposure to periodontitis and severe asthma that was observed even after performing regression models adjusted for nine different sets of potential confounding variables. The adjusted association measurement varied approximately $10 \%$ in relation to the crude measurement, depending on the set of confounders selected for each model. The frequency of periodontitis in the group of participants with severe asthma (46.20\%) was more than twice that found in the control group (22.30\%). These findings are confirmed by previous studies (Gomes-Filho et al., 2014; Laurikainen \& Kuusisto, 1998;
Yaghobee et al., 2008) based on the biological knowledge that connect both diseases.

The biological plausibility of the association between periodontitis and asthma is not well understood. It is known that periodontopathogens activate host immune cells to produce cytokines, such as prostaglandin E2 (PGE2), interferon- $\gamma$, tumor necrosis factor- $\alpha$, and interleukins (IL-1, IL-6, IL-10, IL-11), which stimulate macrophages and osteoclasts to release hydrolases and collagenases, as well as matrix metalloproteinases (MMPs) such MMP-1, MMP-9, and MMP-12 (Gueders et al., 2006). The biologically active molecules have been implicated in bronchial remodeling in asthma by cleaving collagen and elastic fibers within the lung tissue.

Although there is a theoretical support that justifies these findings, other studies did not find this association (Friedrich et al., 2006; Stensson et al., 2011) or observed an inverse association (Rivera et al., 2016).

Previously, six studies explored connections between periodontitis and asthma. Two of them, with larger samples (Friedrich et al., 2006; $-N=2,837-$ only 114 individuals with asthma, Rivera et al., 2016-N = 1,315-only 191, with asthma), used a cross-sectional design, with limitations inherent to this type of study. It is also worth noting that the study by Rivera et al. (2016) included only obese individuals and self-reported asthma information. Only one (GomesFilho et al., 2014-N = 220) of other studies (Laurikainen \& Kuusisto, $1998-N=66$, Yaghobee et al., $2008-N=100$, Stensson et al., $2011-N=40$,) assessed the control of severe asthma in relation to the used therapy, differing from the present study because it included individuals in the case group with partially controlled severe asthma. Stensson et al., 2011; selected 20 individuals with controlled asthma for the study, but did not present the criterion for this classification. It is noteworthy that among previous studies, four adjusted for confounding in their analysis (Friedrich et al., 2006; Gomes-Filho et al., 2014; Laurikainen \& Kuusisto, 1998; Rivera et al., 2016).

Initial data analysis of the present study did not find potential confounding (Rothman, Greenland, \& Lash, 2008). Thus, the selection of potential confounders was based on the following conceptual framework, respecting the criterion of non-collinearity, that is, when a confounding covariable was included in the model, it was the representative of a set of characteristics of the same nature. The covariables, schooling level, family income, household density, representatives of the socioeconomic condition of the participant, could not be simultaneously adjusted in the same model without producing overadjustment. The same reasoning was adopted for other chronic diseases: osteoporosis, hypertension, and diabetes. Regarding the criteria used to avoid overadjustment, each model presented five covariables, representing a ratio of 1:20, approximately, one confounder for every twenty individuals of the case group (Rothman et al., 2008). Please also note that the sample size of the study was greater than the minimum calculated for the investigation.

When it was observed that the association measurement remained strong in the present study, performed with another sample of participants, different analytical models were used, initially considering the confounders of the previous study of Gomes-Filho et al., 2014, to 
TABLE 1 Socioeconomic, demographic, medical, and oral characteristics ( $n[\%])$ of the study groups $(N=260)$

\begin{tabular}{|c|c|c|c|c|c|}
\hline \multirow[b]{2}{*}{ Characteristics } & \multicolumn{2}{|c|}{$\begin{array}{l}\text { Control Group } \\
N=130\end{array}$} & \multicolumn{2}{|c|}{$\begin{array}{l}\text { Severe Asthma } \\
N=130\end{array}$} & \multirow[b]{2}{*}{$p$} \\
\hline & $N$ & $\%$ & $N$ & $\%$ & \\
\hline \multicolumn{6}{|l|}{ Age (years) } \\
\hline$>39$ & 80 & 64.50 & 110 & 84.60 & $<.01$ \\
\hline \multicolumn{6}{|l|}{ Sex } \\
\hline Female & 113 & 86.90 & 104 & 80.00 & .13 \\
\hline \multicolumn{6}{|c|}{ Self-reported skin color } \\
\hline Black/Brown & 104 & 80.00 & 95 & 73.10 & .18 \\
\hline \multicolumn{6}{|c|}{ Schooling level (years of study) } \\
\hline$\leq 4$ years & 39 & 30.00 & 58 & 44.60 & .01 \\
\hline \multicolumn{6}{|c|}{ Household density (number of people) } \\
\hline$>3$ people & 56 & 43.10 & 50 & 38.50 & .45 \\
\hline \multicolumn{6}{|l|}{ Marital status } \\
\hline Without partner & 69 & 53.10 & 68 & 52.30 & .90 \\
\hline \multicolumn{6}{|c|}{ Family income (minimum wages) } \\
\hline$\leq 01$ & 46 & 35.40 & 63 & 48.50 & .03 \\
\hline \multicolumn{6}{|l|}{ Smoking habit } \\
\hline Yes & 4 & 3.10 & 0 & 0 & .06 \\
\hline \multicolumn{6}{|l|}{ Physical activity } \\
\hline No & 89 & 68.50 & 84 & 64.60 & .51 \\
\hline \multicolumn{6}{|l|}{ Last visit to dentist } \\
\hline Never or $\geq 1$ year & 73 & 56.20 & 76 & 58.50 & .71 \\
\hline \multicolumn{6}{|c|}{ Mouth-breathing habit } \\
\hline Yes & 63 & 48.50 & 105 & 80.80 & $<.01$ \\
\hline \multicolumn{6}{|l|}{ Brushing frequency } \\
\hline$<3 \times /$ day & 70 & 53.80 & 64 & 49.20 & .46 \\
\hline \multicolumn{6}{|c|}{ Use of dental floss (at least once a day) } \\
\hline No & 62 & 47.70 & 68 & 52.30 & .27 \\
\hline \multicolumn{6}{|l|}{ Periodontitis } \\
\hline Yes & 29 & 22.30 & 60 & 46.20 & $<.01$ \\
\hline \multicolumn{6}{|l|}{ Arterial hypertension } \\
\hline Yes & 37 & 28.50 & 55 & 42.60 & .02 \\
\hline \multicolumn{6}{|l|}{ Diabetes mellitus } \\
\hline Yes & 9 & 6.90 & 15 & 11.50 & .20 \\
\hline \multicolumn{6}{|l|}{ Osteoporosis } \\
\hline Yes & 4 & 3.10 & 9 & 6.90 & .15 \\
\hline \multicolumn{6}{|c|}{ Hypercholesterolemia } \\
\hline Yes & 18 & 13.80 & 21 & 16.20 & .60 \\
\hline \multicolumn{6}{|c|}{ Cardiovascular disease } \\
\hline Yes & 5 & 3.80 & 7 & 5.40 & .55 \\
\hline \multicolumn{6}{|c|}{ Body mass index $\left(\mathrm{kg} / \mathrm{m}^{2}\right)$} \\
\hline$\geq 25$ & 89 & 68.50 & 93 & 71.50 & .59 \\
\hline
\end{tabular}

explore possible changes that could occur in the association measurement when confounders were selected for the composition of the nine adjusted models.
TABLE 2 Other characteristics related to periodontal condition of the study groups $(N=260)$

\begin{tabular}{|c|c|c|c|}
\hline Clinical parameter & $\begin{array}{l}\text { Control group } \\
N=130\end{array}$ & $\begin{array}{l}\text { Severe asthma } \\
N=130\end{array}$ & $p$ \\
\hline \multicolumn{4}{|c|}{ Bleeding upon probing (\%) } \\
\hline Mean $\pm S D$ & $12.68 \pm 22.5$ & $21.47 \pm 17.7$ & \multirow[t]{2}{*}{$<.01$} \\
\hline Median/Range & $6.40 / 0-100$ & $13.40 / 0-100$ & \\
\hline \multicolumn{4}{|l|}{ Plaque Index (\%) } \\
\hline Mean $\pm S D$ & $29.57 \pm 24.6$ & $44.35 \pm 29.0$ & \multirow[t]{2}{*}{$<.01$} \\
\hline Median/Range & $21.70 / 2.2-100$ & $39.30 / 0-100$ & \\
\hline \multicolumn{4}{|l|}{ Number of teeth $(n)$} \\
\hline Mean $\pm S D$ & $22.68 \pm 7.9$ & $19.79 \pm 8.3$ & \multirow[t]{2}{*}{.05} \\
\hline Median/Range & $24.00 / 4-32$ & $21.00 / 4-32$ & \\
\hline \multicolumn{4}{|c|}{ Number of sites with CAL 1-2 mm (n) } \\
\hline Mean $\pm S D$ & $7.87 \pm 6.5$ & $3.98 \pm 4.7$ & \multirow[t]{2}{*}{.02} \\
\hline Median/Range & $7.00 / 0-26$ & $2.00 / 0-24$ & \\
\hline \multicolumn{4}{|c|}{ Number of sites with CAL 3-4 mm (n) } \\
\hline Mean $\pm S D$ & $9.25 \pm 5.2$ & $8.83 \pm 6.0$ & \multirow[t]{2}{*}{.20} \\
\hline Median/Range & $8.50 / 0-21$ & $8.00 / 0-23$ & \\
\hline \multicolumn{4}{|c|}{ Number of sites with CAL $\geq 5 \mathrm{~mm}(n)$} \\
\hline Mean $\pm S D$ & $1.58 \pm 1.9$ & $1.84 \pm 2.0$ & \multirow[t]{2}{*}{.32} \\
\hline Median/Range & $1.00 / 0-9$ & $1.00 / 0-9$ & \\
\hline \multicolumn{4}{|c|}{ Number of sites with PD $\geq 4 \mathrm{~mm}(n)$} \\
\hline Mean $\pm S D$ & $2.80 \pm 4.0$ & $4.52 \pm 5.0$ & \multirow[t]{2}{*}{.07} \\
\hline Median/Range & $1.00 / 0-22$ & $3.00 / 0-22$ & \\
\hline
\end{tabular}

CAL, clinical attachment level; PD, probing depth.

TABLE 3 Crude and adjusted odds ratio (OR) and 95\% confidence interval $(95 \% \mathrm{Cl})$ for the association between periodontitis and controlled severe asthma $(N=260)$

\begin{tabular}{|llll|}
\hline Model & OR & $95 \% \mathrm{Cl}$ & $\boldsymbol{p}$ \\
\hline Crude & 2.98 & $1.74-5.11$ & $<.01$ \\
\hline Adjusted $^{1}$ & 3.18 & $1.80-5.63$ & $<.01$ \\
\hline Adjusted $^{2}$ & 3.01 & $1.71-5.30$ & $<.01$ \\
\hline Adjusted $^{3}$ & 3.01 & $1.70-5.34$ & $<.01$ \\
\hline Adjusted $^{4}$ & 3.21 & $1.81-5.69$ & $<.01$ \\
\hline Adjusted $^{5}$ & 3.09 & $1.75-5.46$ & $<.01$ \\
\hline Adjusted $^{6}$ & 3.07 & $1.73-5.45$ & $<.01$ \\
\hline Adjusted $^{7}$ & 3.25 & $1.84-5.76$ & $<.01$ \\
\hline Adjusted $^{8}$ & 3.08 & $1.75-5.44$ & $<.01$ \\
\hline Adjusted $^{9}$ & 3.09 & $1.74-5.49$ & $<.01$ \\
\hline
\end{tabular}

Adjusted $^{1}$ for age, schooling level, osteoporosis, smoking habit and BMI. Adjusted $^{2}$ for age, schooling level, hypertension, smoking habit and BMI. Adjusted $^{3}$ for age, schooling level, diabetes, smoking habit and BMI. Adjusted $^{4}$ for age, family income, osteoporosis, smoking habit and BMI. Adjusted $^{5}$ for age, family income, hypertension, smoking habit and BMI. Adjusted $^{6}$ for age, family income, diabetes, smoking habit and BMI.

Adjusted $^{7}$ for age, household density, osteoporosis, smoking habit and BMI. Adjusted $^{8}$ for age, household density, hypertension, smoking habit and BMI. Adjusted $^{9}$ for age, household density, diabetes, smoking habit and BMI. 
The conceptual framework for this study was based on the knowledge that both periodontitis and asthma are more frequent with advancing age (WHO, 2011, Santos et al., 2011). Smoking is known as risk factor for both asthma severity and progression of periodontitis (Albandar, Streckfus, Adesanya, \& Winn, 2000 Gallefoss \& Bakke, 2003). The inflammatory profile of individuals with BMI $>25 \mathrm{~kg} /$ $\mathrm{m}^{2}$ raises the risk for both diseases under investigation (Genco \& Borgnakke, 2013; Gruchala-Niedoszytko, Małgorzewicz, Niedoszytko, Gnacinska, \& Jassem, 2013). With respect to the socioeconomic covariables, the relevance of schooling level, family income, and unfavorable family density as risk factors for both asthma and periodontitis are established (Aranha, Grisi, \& Escobar, 2011; Gomes-Filho et al., 2014). Finally, for chronic diseases, osteoporosis, hypertension, diabetes, although important confounders of the association under study (Campos, Liphaus, Silva, \& Pereira, 2003; Dregan, Charlton, Chowienczyk, \& Gulliford, 2014), only one was included in each model, considering that the sample size of the present study would not support models with a greater number of confounders (Rothman et al., 2008).

Given the importance of the effect of smoking on both asthma and periodontitis (Albandar et al., 2000 Gallefoss \& Bakke, 2003), it is noteworthy that in the present study, only four participants in the control group, without a diagnosis of asthma, reported smoking habit. Thus, the effect of smoking would be restricted to individuals without asthma. Thus, smoking is essentially irrelevant for this sample and we opted to use smoking habit as a dichotomous covariable.

Several limitations of the present study are worth noting. Casecontrol studies, due to their retrospective nature, are vulnerable to recall bias. Thus, the self-reported information provided for the present study, such as diabetes, hypertension, osteoporosis, may have been influenced by time.

Severe asthma requires treatment with medium to high doses of inhaled corticosteroids, which have been used among the individuals of the study (Nascimento-Sampaio et al., 2015; Ponte et al., 2014). Inhaled corticosteroids are the preferred treatment, for the management of persistent asthma, due to their anti-inflammatory effects and topical administration on the airways. As they inhibit the inflammatory response, they may suppress the immune system locally and increase the individual's susceptibility to infection by some pathogens (Santos, Jamelli, Rizzo, \& Sarinho, 2007).

Considering the design of this study, we cannot exclude the possibility of severe asthma being a risk factor for periodontitis (reverse causality), nor an indirect reverse causality. In this latter situation, the reason for the association between periodontitis and asthma might well be that inhaled corticosteroids, in doses considered to be medium to high, can increase the risk of periodontal disease (Hujoel, CunhaCruz, Maupome, \& Saver, 2008). Further, the causality of this association may be bidirectional. Longitudinal studies need to be conducted as the only way to clarify these doubts.

The information concerning the time of use of inhaled corticosteroids, time of asthma diagnosis, and cumulative dose of inhaled corticosteroids has not been presented in this paper, but they were represented by the covariable age of the participant which was employed as a confounder in all adjusted analysis models to neutralize the effect of these characteristics.

In summary, a clear association between exposure to periodontitis and severe asthma has been demonstrated in this case-control investigation. It suggests that chronic periodontal inflammation may contribute to the severity of asthma. These findings have significant potential implications for the individual and for public health and warrant further investments in longitudinal studies designed to sort out a causal link.

\section{ACKNOWLEDGEMENTS}

This study was financed by the Fundação de Âmparo à Pesquisa do Estado da Bahia (FAPESB); Conselho Nacional de Desenvolvimento Científico e Tecnológico (CNPq); and Universidade Estadual de Feira de Santana, Brazil. An additional grant was obtained by an investigator initiated proposal supported by Trust in Science, a GlaxoSmithKline's program.

\section{CONFLICT OF INTEREST}

None to declare.

\section{AUTHOR CONTRIBUTION}

All authors have made substantial contributions to the article.

\section{ORCID}

Isaac Suzart Gomes-Filho (iD http://orcid.org/0000-0002-4270-8491

\section{REFERENCES}

Albandar, J. M., Streckfus, C. F., Adesanya, M. R., \& Winn, D. M. (2000). Cigar, pipe, and cigarette smoking as risk factors for periodontal disease and tooth loss. Journal of Periodontology, 71, 1874-1881.

Aranha, M. A., Grisi, S. J., \& Escobar, A. M. (2011). Relationship between respiratory tract diseases declared by parents and socioeconomic and cultural factors. Revista paulista de pediatria, 29, 352-356.

Arbes, S. J., \& Matsui, E. C. (2011). Can oral pathogens influence allergic disease? Journal of Allergy and Clinical Immunology, 127, 1119-1127.

Campos, L. M., Liphaus, B. L., Silva, C. A., \& Pereira, R. M. (2003). Osteoporose na infância e adolescência. Journal of Pediatrics, 79, 481-488.

Cerveri, I., Cazzoletti, L., Corsico, A. G., Marcon, A., Niniano, R., Grosso, A., ... de Marco, R. (2012). The impact of cigarette smoking on asthma: A population-based international cohort study. International Archives of Allergy and Immunology, 158, 175-183.

Davoodi, P., Mahesh, P. A., Holla, A. D., \& Ramachandra, N. B. (2013). Association of socio-economic status with family history in adult patients with asthma. Indian Journal of Medical Research, 138, 497-503.

Dregan, A., Charlton, J., Chowienczyk, P., \& Gulliford, M. C. (2014). Chronic inflammatory disorders and risk of type 2 diabetes mellitus, coronary heart disease, and stroke: A population-based cohort study. Circulation, $130,837-844$.

Friedrich, N., Völzke, H., Schwahn, C., Kramer, A., Jünger, M., Schäfer, T., ... Kocher, T. (2006). Inverse association between periodontitis and respiratory allergies. Clinical and Experimental Allergy, 6, 495-502. 
Gallefoss, F., \& Bakke, O. S. (2003). Does smoking affect the outcome of patient education and self-management in asthmatics? Patient Education and Counseling, 49, 91-97.

Genco, R. J., \& Borgnakke, W. S. (2013). Risk factors for periodontal disease. Periodontol, 2000(62), 59-94.

GINA (2002). Global initiative for asthma. Global strategy for asthma management and prevention. Retrieved from www.ginasthma.org.

GINA (2014). Global initiative for asthma. Global strategy for asthma management and prevention. Revised 2014. Vancouver, GINA, 2014.

Gomes-Filho, I. S., Cruz, S. S., Rezende, E. J., Dos Santos, C. A., Soledade, K. R., Magalhães, M. A., ... Cerqueira, E. M. (2007). Exposure measurement in the association between periodontal disease and prematurity/ low birth weight. Journal of Clinical Periodontology, 34, 957-963.

Gomes-Filho, I. S., Soledade-Marques, K. R., Seixas da Cruz, S., de Santana Passos-Soares, J., Trindade, S. C., Souza-Machado, A., ... Freitas Coelho, J. M. (2014). Does periodontal infection have an effect on severe asthma in adults? Journal of Periodontology, 85, 179-187.

Gruchala-Niedoszytko, M., Małgorzewicz, S., Niedoszytko, M., Gnacinska, M., \& Jassem, E. (2013). The influence of obesity on inflammation and clinical symptoms in asthma. Advances in Medical Sciences, 58, 15-21.

Gueders, M. M., Foidart, J. M., Noel, A., \& Cataldo, D. D. (2006). Matrix metalloproteinases (MMPs) and tissue inhibitors of MMPs in the respiratory tract: Potential implications in asthma and other lung diseases. European Journal of Pharmacology, 8, 133-144.

Hujoel, P. P., Cunha-Cruz, J., Maupome, G., \& Saver, B. (2008). Long-term use of medications and destructive periodontal disease. Journal of Periodontology, 79, 1330-1338.

Laurikainen, K., \& Kuusisto, P. (1998). Comparison of the health status and salivary flow rate of asthmatic patients with those of nonasthmatic adults-Results of a pilot study. Allergy, 53, 316-319.

Matsui, E. C. (2012). Respiratory symptoms in asthma: The view through a wide-angle lens. Journal of Allergy and Clinical Immunology, 130, 408-492.

Mehta, A., Sequeira, P. S., Sahoo, R. C., \& Kaur, G. (2009). Is bronchial asthma a risk factor for gingival diseases? A control study. New York State Dental Journal, 75, 44-46.

Nascimento-Sampaio, F. S., Leite, M. S., Leopold, D. A., Silva, S. G., Schwingel, P. A., Mendes, C. M., ... Campos, R. A. (2015). Influence of upper airway abnormalities on the control of severe asthma: A cross-sectional study. International Forum of Allergy \& Rhinology, 5, 371-379.

Navarro, V. P., Nelson Filho, P., Silva, L. A. B., \& Freitas, A. C. (2006). O envolvimento das metaloproteinases de matriz no processo fisiopatológico da cavidade oral. Revista de odontologia da UNESP, 35, 233-238.
Papapanou, P. N. (1998). Risk assessment in the diagnosis and treatment of periodontal diseases. Journal of Dental Education, 62, 822-839.

Ponte, E. V., Stelmach, R., Franco, R., Souza-Machado, C., Souza-Machado, A., \& Cruz, A. A. (2014). Age is not associated with hospital admission or uncontrolled symptoms of asthma if proper treatment is offered. International Archives of Allergy and Immunology, 65, 61-67.

Rivera, R., Andriankaja, O. M., Perez, C. M., \& Joshipura, K. (2016). Relationship between periodontal disease and asthma among overweight/obese adults. Journal of Clinical Periodontology, 43, 566-571.

Rothman, K. J., Greenland, S., \& Lash, T. L. (2008). Modern epidemiology, 3rd ed.. Philadelphia, PA: Lippincott, Williams \& Wilkins.

Santos, C. M., Gomes-Filho, I. S., Passos, J. S., Cruz, S. S., Góes, C. S., \& Cerqueira, E. M. (2011). Fatores de risco associados com a doença periodontal em indivíduos internados em um hospital em Feira de Santana. Rev Baiana Saúde Pública, 35, 87-102.

Santos, N. C. N., Jamelli, S. R., Rizzo, J. A., \& Sarinho, E. S. C. (2007). Efeitos relacionados ao uso de esteroides inalados na saúde periodontal que o médico precisa conhecer. Rev Bras Alerg Imunopatol, 30(6), 220-226.

Stensson, M., Wendt, L. K., Koch, G., Oldaeus, G., Ramberg, P., \& Birkhed, D. (2011). Oral health in young adults with long-term, controlled asthma. Acta Odontologica Scandinavica, 69, 158-164.

Wennström, A., Ahlqwist, M., Stenman, U., Björkelund, C., \& Hakeberg, M. (2013). Trends in tooth loss in relation to socio-economic status among Swedish women, aged 38 and 50 years: Repeated cross-sectional surveys 1968-2004. BMC Oral Health, 13, 1-8.

World Health Organization (2011). Global status report on noncommunicable diseases, 2011, pp. 1-176. Geneva, Switzerland: WHO.

Yaghobee, S., Paknejad, M., \& Khorsand, A. (2008). Association between asthma and periodontal disease. Journal of Dentistry, 5, 47-51.

How to cite this article: Soledade-Marques KR, Gomes-Filho

IS, Cruz SSD, et al. Association between periodontitis and severe asthma in adults: A case-control study. Oral Dis. 2017;00:1-7. https://doi.org/10.1111/odi.12737 